\title{
Technical Note- A Novel Approach to Treat Markowitz Type 1 and Type 2 Naso-Orbito Ethmoidal Fractures Using Minimally Invasivetranscutaneo- Periosteal Plates
}

\author{
Arjun Shenoy* \\ Fellow in Cranio-Maxillofacial Trauma, AOMSI, India
}

Submission: September 16, 2017; Published: September 19, 2017

*Corresponding author: Arjun Shenoy, Fellow in Cranio-Maxillofacial Trauma, AOMSI, India, Tel: 8281850777

\section{Introduction}

Displaced Fractures of the Naso-Orbito-Ethmoidal complex have always stood out as a challenge for surgeons owing to their complex articulation in the central midface from the anatomic, aesthetic and functional perspective. In Maxillofacial Trauma, the evolving trends have shown a steady paradigm shift towards minimally invasive procedures when approaching facial fractures from the extra-oral approach. The aim of these minimally invasive procedures has been to achieve restoration of original form and function without compromising the aesthetic outcome. Conventional surgical approaches to the central midface describe incisions which allow for proper visualisation of the fracture fragments to aid in their reduction and fixation. The attachment of the medial canthal ligament to the NOE Complex and its disruption during the fracture play a vital role in the treatment planning and surgical intervention.

Markowitz Type 1 and Type 2NOE fractures can be unilateral or bilateral and are characterized by the medial canthal ligament being attached to a bone fragment which may or may not have significant displacement. The innovative novel approach of transcutaneoperiosteal plates (TCPP system) was conceptualized by the authors as a minimalistic but effective design template to aid in anatomic reduction and dynamic fixation without the need for placing an incision in the treatment of Markowitz Type $1 \& 2$ fractures of the NOE complex fractures. The dynamic fixation refers to the fixation principle which allows for real time manipulation of the template by digital compression in the post-operative period allowing for the moulding of the NOE Complex into its desired form and function. A detailed clinical study of the versatility and viability of the TCCP System was undertaken as a one year clinical study.

\section{Materials and Methods}

To have a universal and appealing application, the TCCP System has been modelled on a template that was readily available and inexpensive. The 4 hole with gap stainless steel and titanium plates served as the basic rigid splint upon which the displaced NOE complex could be re-suspended both with antero-posterior traction and horizontal vector traction. After the plate was in flush mimicking the intended framework to be restored, sutures 4-0 vicryl or nylon is passed through the skin and negotiated through the periosteum of the NOE complex andsuspended over the template with positive traction. The traction suspension allows for post-operative manipulation by digital compression to aid in dynamic remodelling restoring the antero-posterior projection and disrupted intercanthal distance (Figures 1-8).
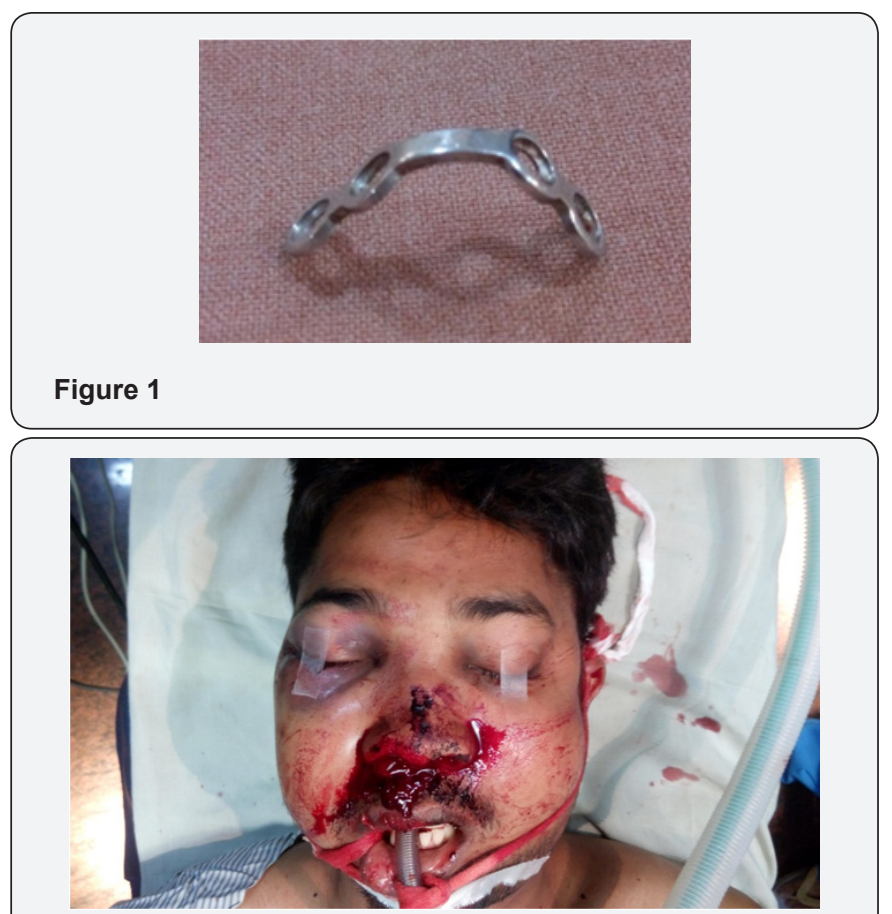

Figure 2 


\section{Global Journal of Otolaryngology}

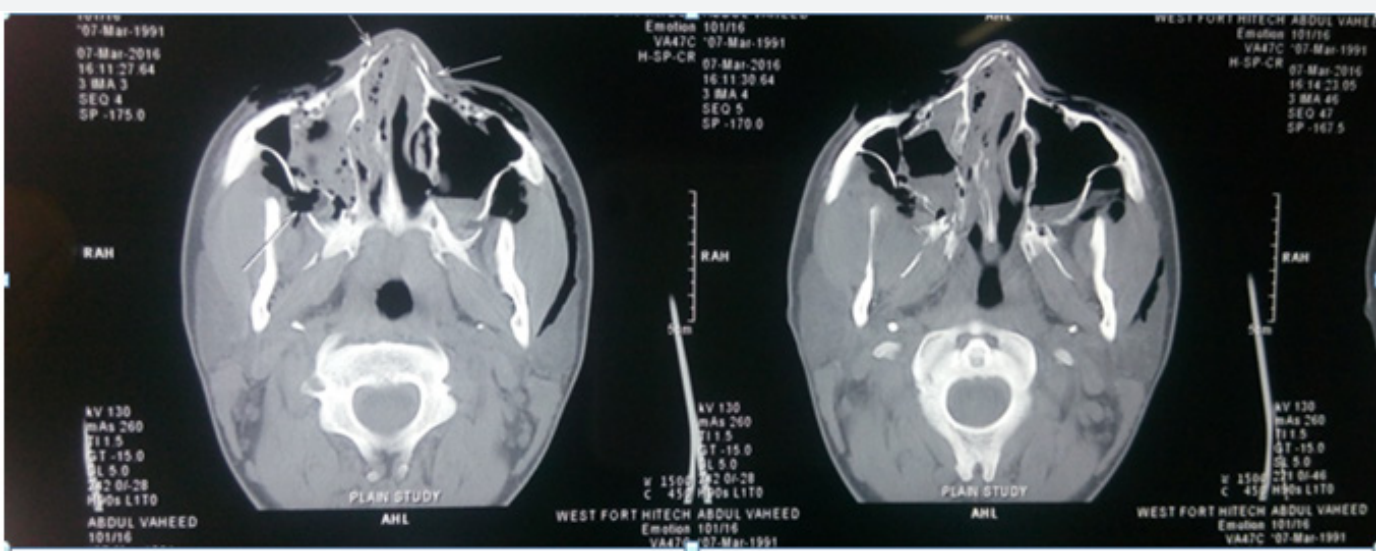

Figure 3
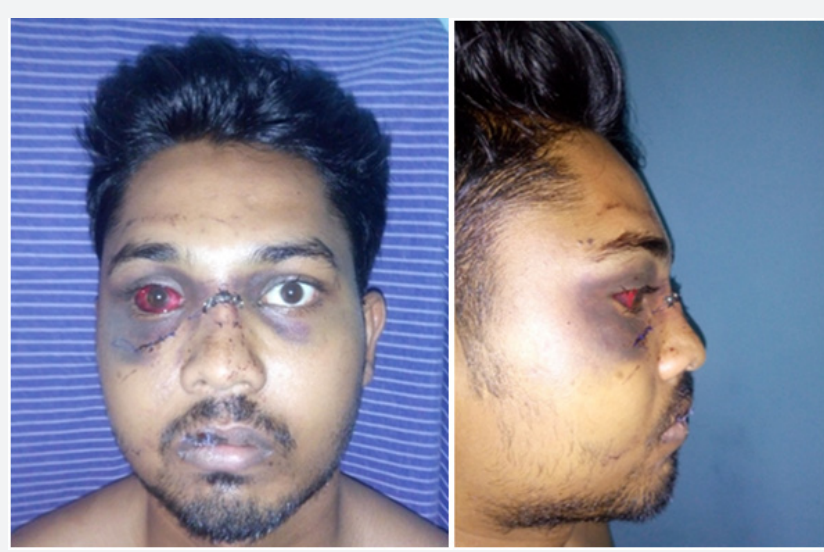

Figure 4

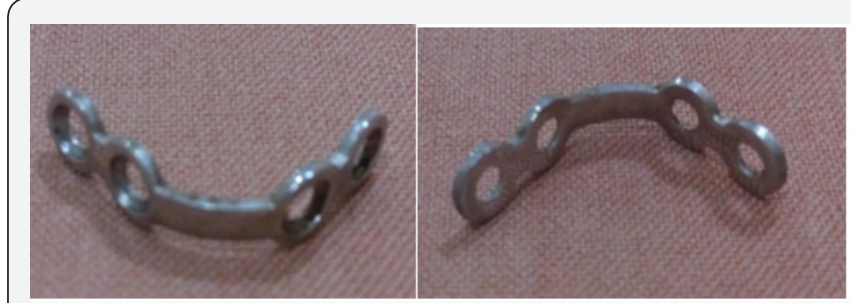

Figure 5

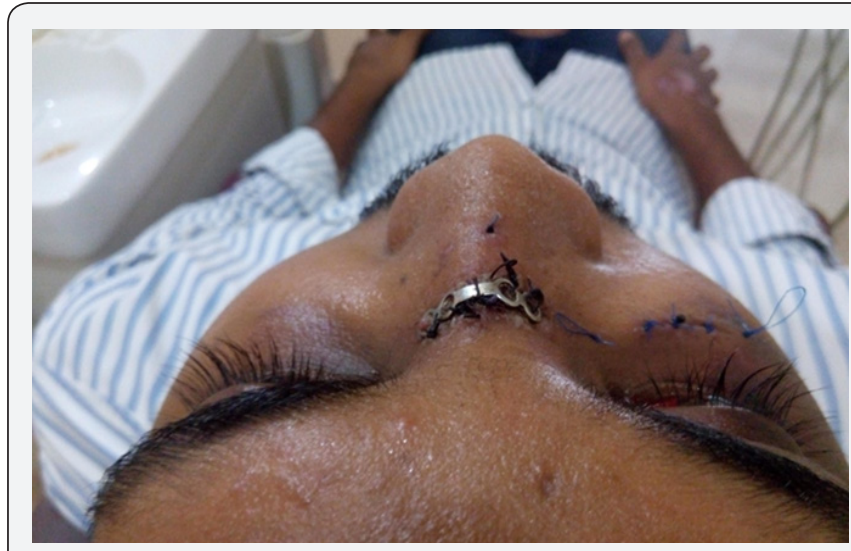

Figure 6

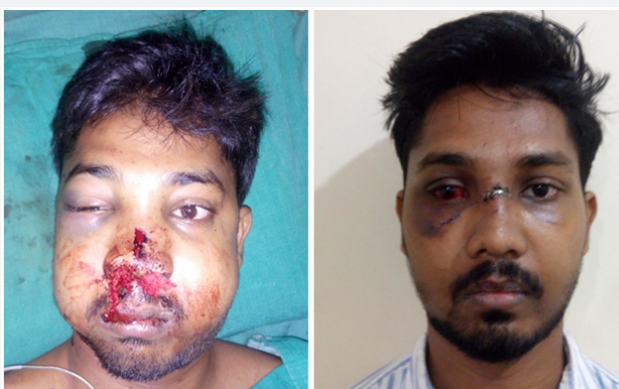

Figure 7

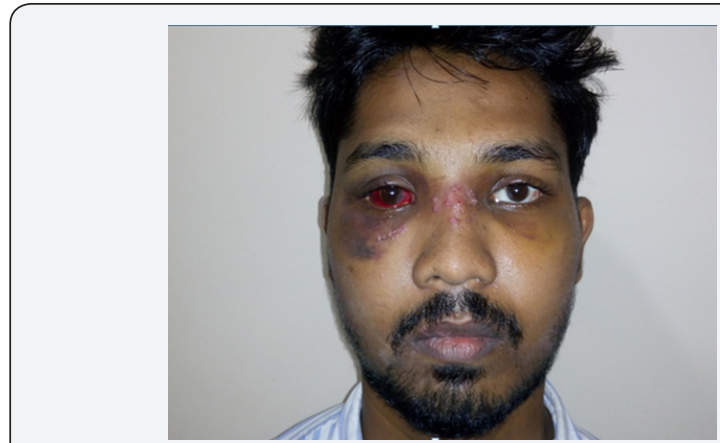

Figure 8

\section{Summary}

The clinical study was performed over a period of one year at a tier 1 trauma centre. The sample sizes of cases were 20 . The cases included both displaced Type 1 Markowitz and type 2 Markowitz fractures of the NOE Complex. Clinical parameters like anteroposterior projection, inter canthal distance, functional nasal airflow, subjective patient satisfaction index and radiographic comparison reinforced statistically the effectiveness of the TCPP System in restoring the form and function of a displaced NOE Complex. The Transcutaneo-periosteal plates have a promising future in minimally invasive interventions regarding fractures involving the central midface, however their limitations are dictated by the detachment of the medial canthal ligament from the Naso-OrbitoEtmoidal Complex. 

(C) Commons Attribution 4.0 License BY DOI: $10.19080 /$ GJ0.2017.10.555790

\section{Your next submission with Juniper Publishers} will reach you the below assets

- Quality Editorial service

- Swift Peer Review

- Reprints availability

- E-prints Service

- Manuscript Podcast for convenient understanding

- Global attainment for your research

- Manuscript accessibility in different formats

( Pdf, E-pub, Full Text, Audio)

- Unceasing customer service

Track the below URL for one-step submission https://juniperpublishers.com/online-submission.php 